\title{
The extent and structure of genetic variation in species of the Sitopsis group of Aegilops
}

\author{
SAMUEL MENDLINGER*广 \& DANIEL ZOHARY $\ddagger$ \\ $\uparrow$ The Institutes for Applied Research, Ben-Gurion University of the Negev, POB 653, Beer Sheva, and $\ddagger$ Department of \\ Genetics, The Hebrew University, Jerusalem, Israel
}

\begin{abstract}
The extent and structure of genetic variation in 21 populations covering the five species of the Sitopsis group of Aegilops were investigated by analysis of electrophoretically discernible water soluble leaf proteins. Sixteen loci were examined. All loci were polymorphic across the five species. Over 40 per cent of the alleles were found in all five species and only three rare alleles were speciesspecific. Genetic diversity was high $(D=0.267)$ with 51 per cent of the total diversity contributed by within-population diversity, 16 per cent by diversity between populations within a species and 33 per cent by diversity between species. Over all 21 populations the mean number of alleles per locus per population was 1.57 and the proportion of polymorphic loci was 0.38 . Aegilops speltoides was genetically distant from the other four species, Ae. bicornis, Ae. longissima, Ae. searsii and $A e$. sharonensis. Aegilops sharonensis was found to be equally close to Ae. longissima and Ae. bicornis. Aegilops searsii was equally distant from Ae. longissima, Ae. bicornis and Ae. sharonensis.
\end{abstract}

Keywords: Aegilops, electrophoresis, genetic diversity, germplasm collection, species relationships.

\section{Introduction}

The quantification of the extent and structure of genetic variation and the different patterns that it takes in populations of wild plants is essential for: (i) an understanding of the processes of evolution; (ii) the development of appropriate and efficient strategies for conservation; and (iii) the collection and preservation of wild and/or weedy relatives of important crops (Frankel \& Bennett, 1970; Frankel \& Hawkes, 1975; Simmonds, 1976). As a model for obtaining information on these questions, few species or species groups are as good as the species of the wheat group (species of the Triticum-Aegilops group in its broadest sense, including cultivated and wild wheats and goatgrasses; Zohary, 1965). The wild species have fairly well defined distributions; morphotypes have been described; in most species populations of different sizes can be easily found; and information on genetic variation in some species is already known (Zohary \& Imber, 1963; Riley, 1965; Zohary, 1965; Sears, 1969; Segal et al., 1980; Brody \& Mendlinger, 1980; Nevo et al., 1982, 1988).

*Correspondence.
In addition to the wheat group's importance in understanding the above, the wild species are also important for our ability to introgress their economically useful genes into cultivated wheat (Zohary et al., 1969; Dvorak et al., 1985; Cox et al., 1990; Dyck et al., 1990). This is especially true for the putative diploid progenitors of $T$. durum and $T$. aestivum: (i) A genome, T. monococcum L. and/or T. urartu Tum. (Melburn \& Thompson, 1927; Gill \& Kimber, 1974; Chapman et al., 1976; Dvorak et al., 1988); (ii) B genome, one of the five species of the Sitopsis group, Ae. speltoides Taush, Ae. bicornis Jaup et Sp., Ae. sharonensis Eig, Ae. longissima Schwein and Ae. searsii Feld. and Kislev (Riley et al., 1958; Johnson, 1975; Feldman \& Kislev, 1977; Kushnir \& Halloran, 1981; Tsunewaki \& Ogihara, 1983; Nath et al., 1984; Kerby et al. 1990); (iii) D genome, Ae. squarrosa L. (Pathak, 1940; Sears, 1948).

All five Sitopsis species are found in Israel. They form a series of isolated or semi-isolated populations which range in size from a few plants to several thousand. The five species of the Sitopsis group are all annual diploids $(2 n=14)$ and, except for $A e$. speltoides, are predominantly autogamous (Zohary \& Imber, 1963). The exact species relationships within 
the Sitopsis group have been the focus of a number of studies which have produced several possible phylogeny trees (Morris \& Sears, 1967; Johnson, 1975; Feldman \& Kislev, 1977; Brody \& Mendlinger, 1980; Bahrman et al., 1988; Vakhitov \& Gimalov, 1988; Yen \& Kimber, 1990). In spite of the importance of this group for wheat breeding and of the numerous studies attempting to determine species relationships, relatively little is known about the extent and structure of genetic variation within species and populations.

In this study, electrophoretically discernible water soluble proteins were examined for 16 loci in $21 \mathrm{popu}-$ lations covering all five Sitopsis species to determine the extent and structure of their genetic variation and the degree of genetic diversity.

\section{Materials and methods}

Twenty-one populations, three of Aegilops speltoides, two of Ae. bicornis, eight of Ae. longissima, three of $A e$ searsii and five of Ae. sharonensis were collected and screened. The locality of each population in Israel, numbered 1-21, is presented in Fig. 1. The populations were carefully chosen to represent the ecological and geographical complexity of each species in Israel. From each population between 30-100 spikes, each taken from a different plant, were collected and separately bagged. Where possible, in each population spikes were collected 2-3 m apart along one or two transects.

Sixteen electrophoretically discernible water soluble leaf proteins were analysed using horizontal starch gel electrophoresis. The protocol and recipes follow Brody \& Mendlinger (1980). One seed per spike was germinated on moist cotton and grown at room temperature next to a window. Leaves from 2-weekold plants were cut, ground in distilled water and the extract absorbed on filter paper wicks which were inserted into the starch gel. The gel was a 13 per cent starch solution (Sigma starch). Each gel contained the extract of five plants from each of three different populations plus a check plant. After electrophoresis, the gels were removed from their moulds, sliced horizontally into three sections and each section stained for a specific protein. After staining, the isozyme patterns of each slice were read by the same two people. All gels were fixed with 10 per cent acetic acid and stored at $4^{\circ} \mathrm{C}$. At the end of the study all gels were reread by the same two people.

Two buffer systems were used, Poulik and TM. The 16 proteins examined were (the buffer systems employed are in brackets): phosphoglucomutase, PGM (TM); phosphoglucose isomerase, PGI (Poulik); malate dehydrogenase, $\mathrm{MDH}$, two loci (TM); malic enzyme, ME (TM); glutamate dehydrogenase, GDH (Poulik);

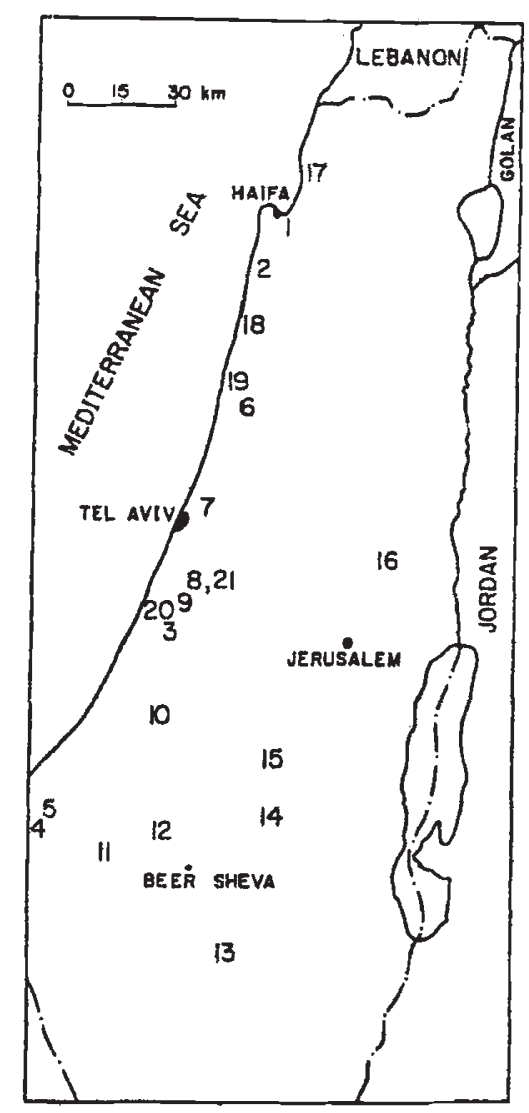

Fig. 1 The locality of each of the 21 Sitopsis group populations in Israel.

indole phenol oxidase, IPO, two loci (Poulik); 6-phosphogluconate dehydrogenase, 6-PGD, two loci (TM); adenylate kinase, AK (TM); hexokinase, HK (TM); glucose-6-phosphate dehydrogenase, G-6-PDH, two loci (TM); catalase, CAT (TM); and general protein (probably the major Ribusco subunit), GP (Poulik).

The extent of genetic variation was quantified by determining in each population and species the mean number of alleles per locus, $A$, and the proportion of polymorphic loci, $P$, at the 1 per cent level of allele presence. Nei's coefficient of genetic identity, $I$, was used to calculate the genetic relationship between the 21 populations and between the five species (Nei, 1972). The extent of genetic diversity for each locus, $D$, was calculated as $D=1-\Sigma p_{i}^{2}$ where $p_{i}$ is the frequency of each allele at a locus in the population. The total genetic diversity was partitioned for each locus into that resulting from intrapopulation diversity $\left(D_{\text {pop }}\right)$, interpopulation diversity within a species $\left(D_{\mathrm{sp}}\right)$ and between-species diversity $\left(D_{\text {sit }}\right)$, (Lewontin, 1972).

Multiple regression analysis and correlations were performed to determine the relationship between allelic frequencies and major ecological and climatological parameters including rainfall, minimum and 
maximum winter and summer temperatures, soil type and altitude (data not presented). All comparisons between groups were via the appropriate analysis of variance.

\section{Results}

All loci were found to be polymorphic, although not in all populations (Table 1) nor in all five species (Table 2). Three patterns of polymorphism were found for the 16 loci:

1 the presence of an ubiquitous allele that was also the predominant allele in almost all, if not all, populations over all five species $\left(P G M_{b}, M D H-1_{c}, 6-P G D-2_{b}, H K_{b}\right.$, $A K_{b}, C A T_{b}$ and $\left.G P_{b}\right)$ together with one or more low frequency alleles found in several populations;

2 the presence of different predominant alleles in different species (G-6-PDH-1 and 2, IPO-1 and 2 and $P G I)$;

3 the presence of considerable within- and betweenpopulation genetic variation and the absence of a predominant allele ( $M D H-2,6-P G D-1$ and $G D H)$.

Only four alleles were found to be species-specific, $P G I_{d}, 6-P G D-1_{a}$ and $C A T_{c}$, and all except $M D H-2_{d}$ were rare. No significant correlation was found between the frequency of any allele and any ecological or climatological parameter. All multiple regression analyses were found not to be significant.

The observed number of heterozygotes $\left(H_{\mathrm{o}}\right)$, the expected number of heterozygotes under panmixia $\left(H_{\mathrm{e}}\right)$ and the coefficient of inbreeding $(F)$ for each of the 15 nuclear loci are presented in the first three columns in Table 3 . The ratio of the observed to the expected number of heterozygotes was only 0.08 . Fourteen of the 15 loci did not significantly differ from each other, with $P G I$ having a statistically higher proportion of observed heterozygotes than the other loci (0.28 of expected). The next four columns of Table 3 present the genetic diversity for each locus $(D)$ and the percentage of the total genetic diversity contributed by within-population effects, between populations of a species and between-species diversity. The mean diversity was 0.267 . Over all loci, 51 per cent of the total genetic diversity was contributed by diversity within a population, 16 per cent by diversity between populations in a species and 33 per cent by diversity between species.

The loci can be divided into three groups:

1 low diversity loci $(D<0.10),(P G M, 6-P G D-2, A K$, $H K$ and $C A T$ );

2 medium diversity loci $(0.10<D<0.30),(G-6-P D H-1$ and 2, $M D H-1, M E$ and $I P O-1)$;

3 high diversity loci $(D>0.30), \quad(P G I, \quad M D H-2$, 6-PGD-1, IPO-2 and $G D H)$.
The low diversity loci all had a predominant ubiquitous allele in all populations together with one or more low frequency alleles which were found in several populations over two or more species. Thus most of the genetic diversity for these loci was found within populations (64 per cent) and much less between populations within a species ( 20 per cent) and between species (16 per cent). For the medium diversity loci, most of the diversity was contributed by alleles that were almost exclusively found in only one species. Consequently, the within-population component of diversity was relatively low (33 per cent) but the between-species component was high (54 per cent). The high diversity loci, with the exception of IPO-2, had a pattern of genetic diversity similar to that of low diversity loci with most of the diversity found within populations (64 per cent) and less between populations of a species (17 per cent) and between species (19 per cent).

The mean genetic identities between populations of the same species were higher than those between populations of different species (Table 4). Aegilops speltoides had the lowest genetic identity with the other species, $0.705-0.795$, vs. 0.855 or more among the other four species. Aegilops sharonensis had almost identically high genetic identities with Ae. longissima and $A e$. bicornis. Aegilops searsii had similar genetic identities with Ae. bicornis, Ae. longissima and Ae. sharonensis.

Most populations, regardless of location, size or species, had similar levels of genetic variation (Table 5). The mean number of alleles per locus, $A$, was 1.76 and the mean per cent polymorphic loci, $P$, was 46 per cent. The structure of genetic variation in most populations was similar with about half or slightly more loci in a population being polymorphic, usually with 2-3 alleles per polymorphic locus. Neither $A$ nor $P$ was significantly different among the five species. Populations from xeric environments (Kerem Shalom, Nir Itschak, Urim, Gilat, Yeruham, Yatir, Taiyiba) had the same pattern of genetic variation as populations from more mesic environments. Significant correlations were found between sample size and $A$ and $P$, but the associations were weak $\left(r^{2}=0.40\right.$ and 0.29 , respectively). No significant correlations were found between environmental parameters and $A$ or $P$. The percentage of observed heterozygous loci, $H_{\mathrm{o}}$, was much smaller than that expected, $H_{\mathrm{e}}$, in all populations. Aegilops speltoides had significantly higher $H_{\mathrm{o}}$ than the other species. No significant differences were found for $H_{\mathrm{e}}$.

All populations except Caramy and Ashdod ( $A e$. sharonensis) had high genotype diversity, with a mean of 0.87 (Table 6). The genotype pattern in most populations was to have one genotype at high 


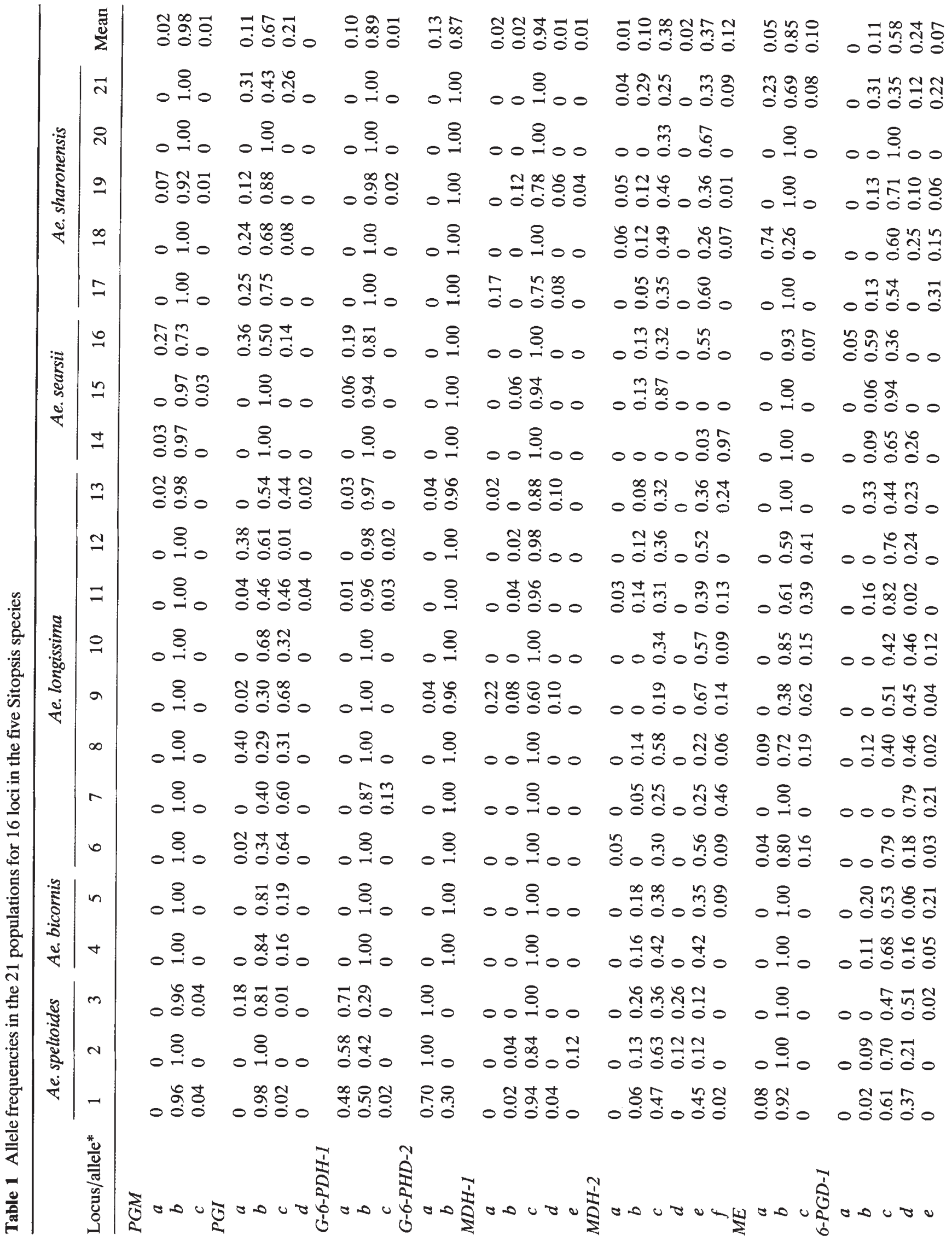




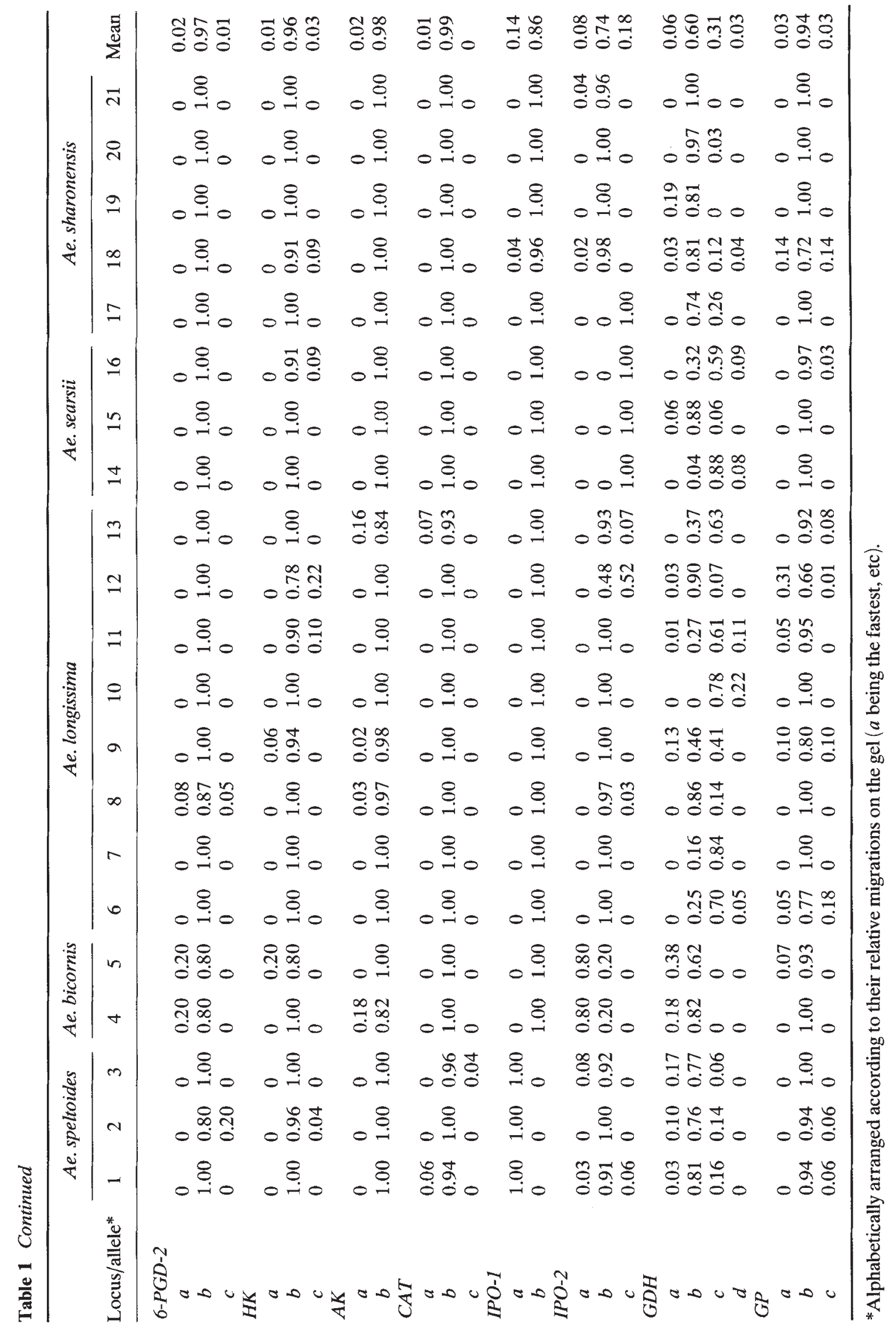


Table 2 Mean allele frequencies in the five species of the Sitopsis group

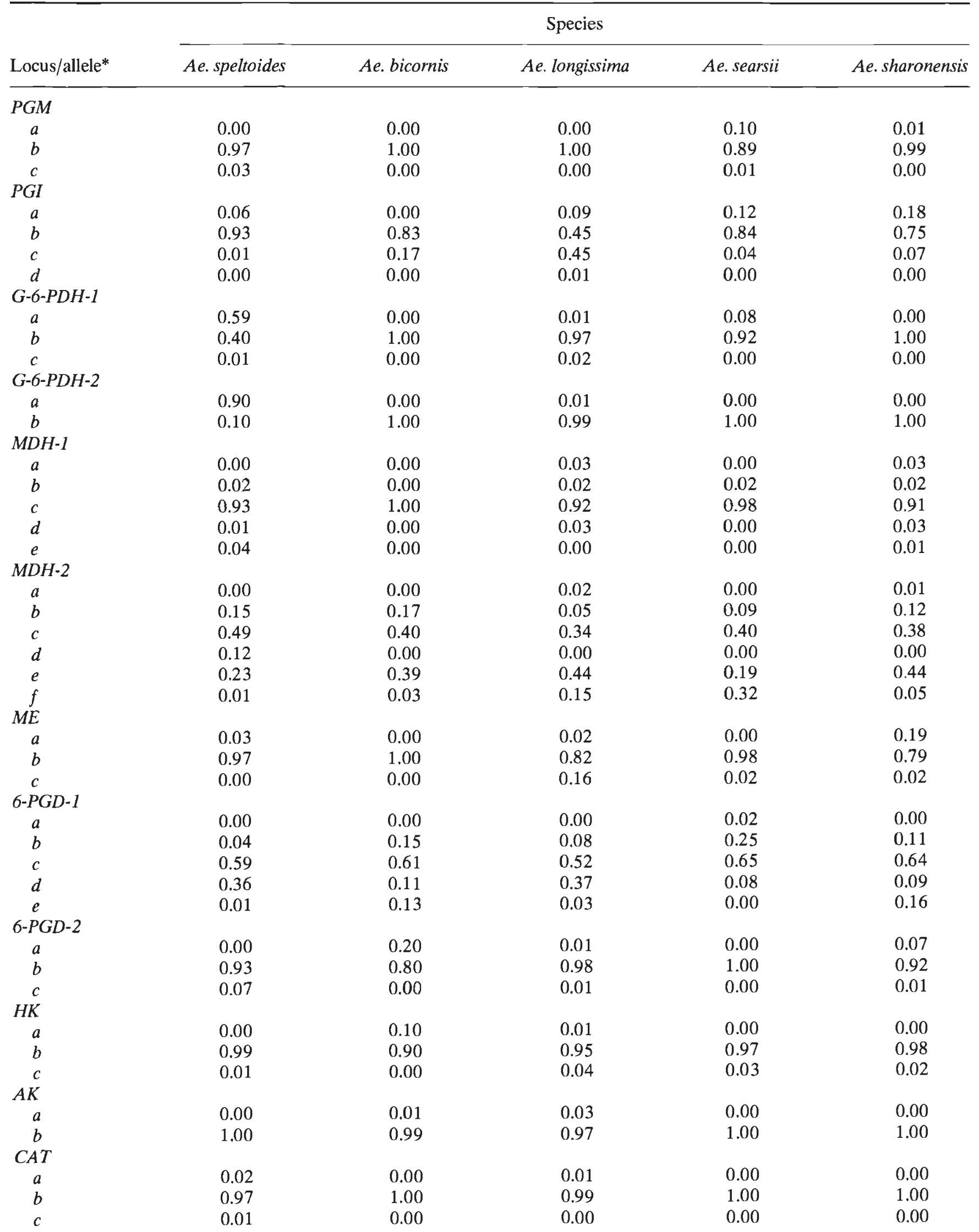


Table 2 Continued

\begin{tabular}{|c|c|c|c|c|c|}
\hline \multirow[b]{2}{*}{ Locus/allele* } & \multicolumn{5}{|c|}{ Species } \\
\hline & Ae. speltoides & Ae. bicornis & Ae. longissima & Ae. searsii & Ae. sharonensis \\
\hline \multicolumn{6}{|l|}{$I P O-1$} \\
\hline$a$ & 1.00 & 0.00 & 0.00 & 0.00 & 0.01 \\
\hline$b$ & 0.00 & 1.00 & 1.00 & 1.00 & 0.99 \\
\hline \multicolumn{6}{|l|}{$I P O-2$} \\
\hline$a$ & 0.04 & 0.80 & 0.00 & 0.00 & 0.01 \\
\hline$b$ & 0.94 & 0.20 & 0.87 & 0.00 & 0.99 \\
\hline$c$ & 0.02 & 0.00 & 0.13 & 1.00 & 0.00 \\
\hline \multicolumn{6}{|l|}{$G D H$} \\
\hline$a$ & 0.10 & 0.28 & 0.02 & 0.02 & 0.04 \\
\hline$b$ & 0.78 & 0.72 & 0.41 & 0.41 & 0.92 \\
\hline$c$ & 0.12 & 0.00 & 0.52 & 0.51 & 0.03 \\
\hline$d$ & 0.00 & 0.00 & 0.05 & 0.06 & 0.01 \\
\hline \multicolumn{6}{|l|}{$G P$} \\
\hline$a$ & 0.00 & 0.03 & 0.06 & 0.00 & 0.03 \\
\hline$b$ & 0.96 & 0.97 & 0.89 & 0.99 & 0.94 \\
\hline$c$ & 0.04 & 0.00 & 0.05 & 0.01 & 0.03 \\
\hline
\end{tabular}

*Alphabetically arranged according to their relative migrations on the gel ( $a$ being the fastest).

Table 3 The observed $\left(H_{\mathrm{o}}\right)$ and expected $\left(H_{\mathrm{e}}\right)$ number of heterozygotes, coefficient of inbreeding $(F)$ and the genetic diversity $(D)$ and its components for 15 loci examined for the five species of the Sitopsis group (see text for details)

\begin{tabular}{|c|c|c|c|c|c|c|c|}
\hline \multirow[b]{2}{*}{ Locus } & \multirow[b]{2}{*}{$H_{\mathrm{o}}$} & \multirow[b]{2}{*}{$H_{\mathrm{e}}$} & \multirow[b]{2}{*}{$F$} & \multirow[b]{2}{*}{$D$} & \multicolumn{3}{|c|}{ Sitopsis group } \\
\hline & & & & & $\begin{array}{l}\text { Within } \\
\text { pops }\end{array}$ & $\begin{array}{c}\text { Between } \\
\text { pops }\end{array}$ & $\begin{array}{c}\text { Between } \\
\text { species }\end{array}$ \\
\hline$P G M$ & 2 & 29 & 0.93 & 0.039 & 0.61 & 0.13 & 0.26 \\
\hline$P G I$ & 72 & 256 & 0.72 & 0.495 & 0.56 & 0.15 & 0.29 \\
\hline$G-6-P D H-1$ & 1 & 30 & 0.97 & 0.198 & 0.54 & 0.07 & 0.39 \\
\hline$G-6-P D H-2$ & 0 & 12 & 1.00 & 0.226 & 0.13 & 0.07 & 0.80 \\
\hline$M D H-1$ & 1 & 84 & 0.99 & 0.115 & 0.49 & 0.20 & 0.31 \\
\hline$M D H-2$ & 16 & 427 & 0.96 & 0.694 & 0.72 & 0.19 & 0.09 \\
\hline$M E$ & 2 & 64 & 0.97 & 0.265 & 0.30 & 0.22 & 0.48 \\
\hline 6-PGD-1 & 28 & 357 & 0.92 & 0.589 & 0.75 & 0.15 & 0.10 \\
\hline $6-P G D-2$ & 2 & 31 & 0.94 & 0.059 & 0.61 & 0.22 & 0.17 \\
\hline$H K$ & 0 & 31 & 1.00 & 0.077 & 0.75 & 0.23 & 0.02 \\
\hline$A K$ & 0 & 16 & 1.00 & 0.039 & 0.67 & 0.25 & 0.08 \\
\hline$C A T$ & 2 & 12 & 0.83 & 0.020 & 0.59 & 0.15 & 0.26 \\
\hline$I P O-1$ & 0 & 2 & 1.00 & 0.241 & 0.17 & 0.10 & 0.73 \\
\hline$I P O-2$ & 3 & 27 & 0.89 & 0.414 & 0.22 & 0.22 & 0.68 \\
\hline$G D H$ & 11 & 243 & 0.95 & 0.539 & 0.57 & 0.57 & 0.25 \\
\hline Mean & 9 & 106 & 0.91 & 0.267 & 0.51 & 0.16 & 0.33 \\
\hline
\end{tabular}

frequency together with many genotypes found at low frequency. The high frequency genotype at all populations was always a combination of the most common alleles at the 16 loci. No significant differences were found between mesic and xeric populations nor between small and large populations.

\section{Discussion}

The extent of genetic variation found within the populations and species examined in this study is greater than previously reported in Sitopsis species (Johnson, 1972; Nakai, 1979; Brody \& Mendlinger, 1980; 
Table 4 Mean $( \pm$ SE) of the coefficients of genetic identity, $I$, for the five species over 21 populations of the Sitopsis group

\begin{tabular}{|c|c|c|c|c|c|}
\hline Species & Ae. speltoides & Ae. bicornis & Ae. longissima & Ae. searsii & Ae. sharonensis \\
\hline Ae. speltoides & $0.951 \pm 0.002$ & $0.735 \pm 0.007$ & $0.757 \pm 0.006$ & $0.705 \pm 0.013$ & $0.795 \pm 0.006$ \\
\hline Ae. bicornis & & $0.983 \dagger$ & $0.883 \pm 0.006$ & $0.869 \pm 0.011$ & $0.920 \pm 0.006$ \\
\hline Ae. longissima & & & $0.939 \pm 0.006$ & $0.855 \pm 0.036$ & $0.925 \pm 0.004$ \\
\hline Ae. searsii & & & & $0.907 \pm 0.008$ & $0.855 \pm 0.005$ \\
\hline Ae. sharonensis & & & & & $0.962 \pm 0.006$ \\
\hline
\end{tabular}

†Only two populations compared.

Table 5 The altitude, mean annual rainfall, mean number of alleles per locus $(A)$, proportion of polymorphic loci $(P)$, observed proportion of heterozygous loci $\left(H_{\mathrm{o}}\right)$, expected proportion of heterozygous loci $\left(H_{\mathrm{e}}\right)$ and inbreeding coefficient $(F)$ for the 21 populations examined in the five species of the Sitopsis group

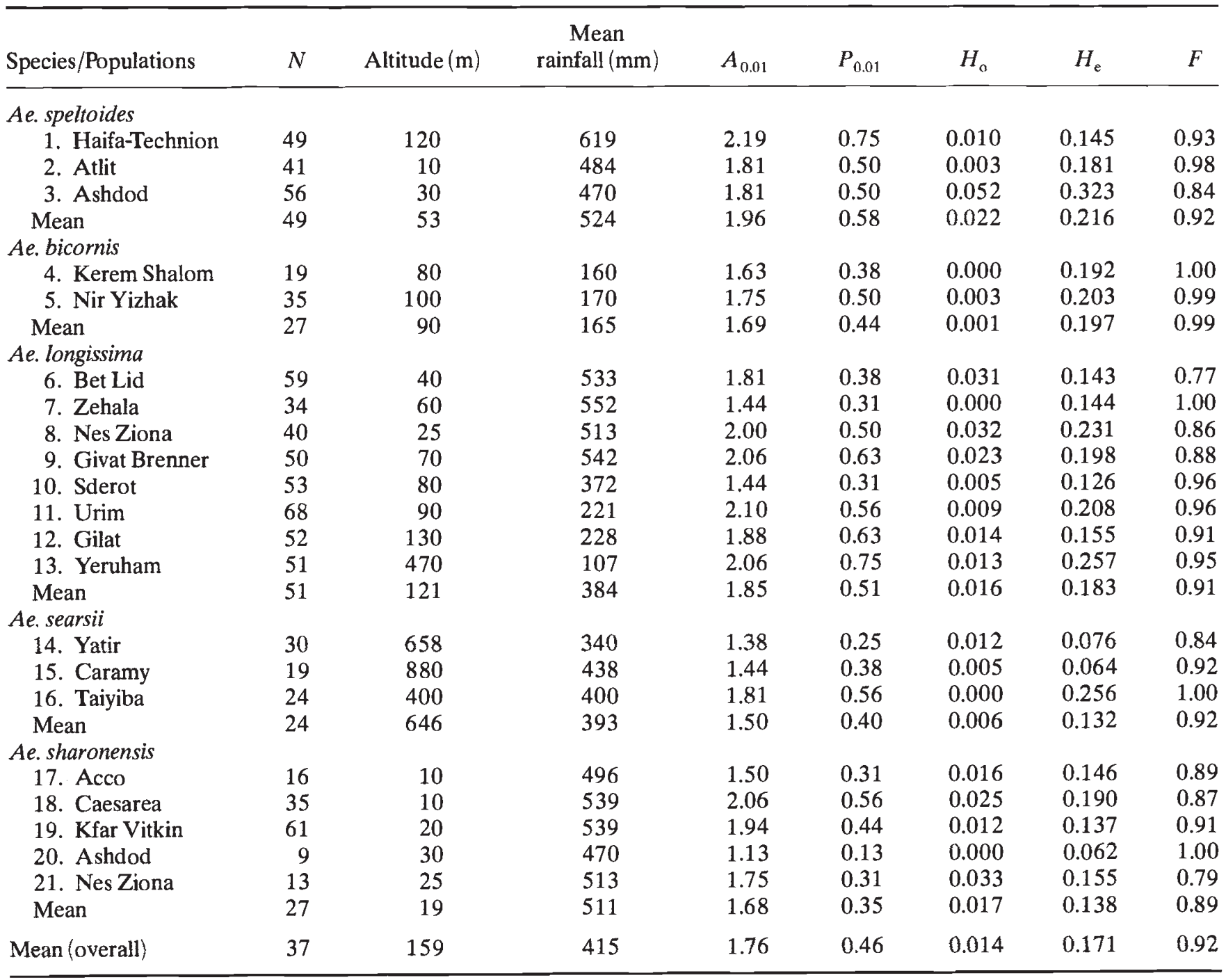


Table 6 The number of plants of each genotype found of the 21 populations examined of the 5 species of the Sitopsis group and $D$, the amount of genotype diversity

\begin{tabular}{|c|c|c|c|c|c|c|c|c|c|c|c|c|c|}
\hline \multirow[b]{2}{*}{ Populations } & \multirow{2}{*}{$\begin{array}{l}\text { Number of } \\
\text { genotypes }\end{array}$} & \multicolumn{12}{|c|}{ Number of plants of each genotype in the sample } \\
\hline & & 1 & 2 & 3 & 4 & 5 & 6 & 7 & 8 & 9 & 10 & 11 & $D$ \\
\hline 1. Haifa-Technion & 20 & 13 & 4 & 1 & & 1 & & & & & 1 & & 0.89 \\
\hline 2. Atlit & 18 & 15 & 2 & & & & & 1 & & & & & 0.89 \\
\hline 3. Ashdod & 27 & 16 & 6 & 3 & 1 & & 1 & & & & & & 0.95 \\
\hline 4. Kerem Shalom & 8 & 5 & 1 & & & 1 & 1 & & & & & & 0.79 \\
\hline 5. Nir Yizhak & 14 & 8 & 2 & 2 & & 1 & & & & & 1 & & 0.87 \\
\hline 6. Bet Lid & 24 & 12 & 8 & 1 & 2 & & & & 1 & & & & 0.91 \\
\hline 7. Zehala & 14 & 10 & 2 & 1 & & & & 1 & & & & & 0.87 \\
\hline 8. Nes Ziona & 33 & 26 & 7 & & & & & & & & & & 0.97 \\
\hline 9. Givat Brenner & 32 & 20 & 6 & 4 & & & 1 & & & & & & 0.95 \\
\hline 10. Sderot & 19 & 7 & 3 & 3 & 3 & 2 & & & & & 1 & & 0.92 \\
\hline 11. Urim & 34 & 23 & 6 & 3 & & & & & & & 1 & 1 & 0.93 \\
\hline 12. Gilat & 25 & 14 & 5 & 2 & 3 & & & 1 & & & & & 0.94 \\
\hline 13. Yeruham & 32 & 20 & 8 & 2 & 2 & & & & & & & & 0.96 \\
\hline 14. Yatir & 9 & 4 & 2 & 1 & & 1 & & 1 & & & & & 0.82 \\
\hline 15. Caramy & 6 & 5 & & & & & & & & & & 1 & 0.51 \\
\hline 16. Taiyiba & 16 & 12 & 1 & 3 & & & & & & & & & 0.92 \\
\hline 17. Acco & 12 & 10 & & 2 & & & & & & & & & 0.89 \\
\hline 18. Caesarea & 25 & 22 & 1 & 1 & & 1 & & & & & & & 0.94 \\
\hline 19. Kfar Vitkin & 29 & 19 & 5 & 2 & 2 & & 1 & & & & & & 0.93 \\
\hline 20. Ashdod & 3 & 1 & 1 & & & & 1 & & & & & & 0.49 \\
\hline 21. Nes Ziona & 9 & 6 & 2 & 1 & & & & & & & & & 0.86 \\
\hline
\end{tabular}

Nishikawa, 1983). However, almost all previous studies have examined genetic variation in accession lines and not populations. Accession lines usually contain less genetic variation than their founding population, as (i) most accession lines originate from relatively few plants, and (ii) many accessions have undergone regeneration and/or seed increase, usually using seed from only a few plants. The amount of genetic variation found in the Sitopsis species was similar to that found in most other autogamous plant species but the extent of genetic diversity was higher (Nevo et al., 1979; Hamrick, 1983). In the tetraploid wild wheat, Triticum dicoccoides, Nevo et al. (1982, 1988 ) found levels of genetic variation similar to that found in this study but only a third of the genetic diversity found in any Sitopsis species $(0.057$ vs. 0.174 ), with a greater proportion of the genetic diversity found in $T$. dicoccoides being between populations ( 37 per cent vs. 24 per cent) and less within populations (63 per cent vs. 76 per cent). Hamrick (1983) surveyed 122 studies covering 91 plant species and found less genetic diversity within populations ( 56 per cent vs. 75 per cent) and more between populations of a species ( 44 per cent vs. 25 per cent) than this study.
This may be because of the large number of low frequency alleles found in the present study that were not unique to any population. Three hypotheses can be invoked to explain, in part or in whole, the richness and pattern of the genetic variation and diversity.

1. Stochastic processes or the neutrality model.

2. Selection via an environmental parameter operating directly on alleles and/or allele complexes.

3. Frequency-dependent selection.

If stochastic processes are the primary cause of the extent and structure of genetic variation, the probability of any allele being lost from a population is a function of allele frequency and population size (Kimuru \& Ohta, 1971). Therefore, alleles at low frequency have a higher probability of being lost from small populations than from large populations. If this loss occurs, it should decrease both the total diversity and the withinpopulation component of diversity in small populations and for low diversity loci as compared to high diversity loci. The equality of the within- and betweenpopulation components for both low and high diversity loci and between small vs. large populations as well as the extensive distribution of low frequency alleles do not support this hypothesis. 
The second hypothesis is the selection of specific alleles/genotypes; i.e. the extent and structure of genetic variation is a function of one or more environmental and/or climatological parameters over space and/or time. Selection over space can be both a macroor microhabitat phenomenon. Nevo et al. $(1982,1988)$ found significant correlations between allele frequencies and climatological parameters in $T$. dicoccoides, and Nevo et al. (1979) in Hordeum spontaneum populations. In the present study no significant correlations have been found between environment and allele frequencies. However, microhabitat selection may be occurring. The populations in this study were usually environmentally complex and contained several microhabitats. Microenvironmental selection under similar conditions was found in Avena barbata (Allard et al., 1972), in Bromus (Brown et al., 1976) and in Liatris cylindracea (Schaal, 1975).

The third hypothesis is frequency-dependent selection. Lewontin (1974) and DeBenedictis (1978) suggested that rare genotypes may have a selective advantage because of their rarity so that they remain in the population rather than become extinct via stochastic processes. If frequency-dependent selection is operating on a plant population, the population would contain considerable genetic variation and high diversity, which is what was found in this study. Nevo et al. (1991) showed that populations of $T$. dicoccoides contain several genotypes that differ in their rates of photosynthesis and they hypothesized that these may be selected for different degrees of shading. Segal $e t a l$. (1980) found that wild populations of Avena and Hordeum are composites of many genotypes, each with a different array of genes for disease control.

The results of this study suggest that the maintenance of much of the genetic variation and its structure is primarily an intrapopulation phenomenon and not an interpopulation one. Whether this is because of microhabitat selection or frequency-dependent selection, or a combination of both, cannot be concluded from the results.

Previous studies examining the relationships between the Sitopsis species have differed in their conclusions. Vakhitov \& Gimalov (1988) compared the 5S ribosomal RNA and Kerby \& Kuspira (1988), using cytogenetic evidence, concluded that the five species were more or less equally related to one another. Yen \& Kimber (1990) used another cytogenetic technique and found that (i) Ae. sharonensis is equally related to $A e$. speltoides and $A e$. longissima and more distantly related to Ae. searsii and Ae. bicornis; (ii) Ae. bicornis is most closely related to Ae. speltoides and most distantly related to Ae. sharonensis; and (iii) Ae. searsii is equally, but not closely, related to Ae. longissima, Ae. speltoides and Ae. bicornis. Brody \& Mendlinger (1980) examined electrophoretic genetic variation and found that $A e$. speltoides was equally but distantly related to Ae. sharonensis, Ae. longissima and Ae. bicornis, with the latter three species equally and closely related to one another. The genetic relationship between the five Sitopsis species found in this study can be summarized as follows.

1. Aegilops speltoides is equally distant from the other four species.

2. Both Ae. sharonensis and Ae. searsii are true species.

3. Aegilops sharonensis is equally close to Ae. longissima and Ae. bicornis and further from $A e$. searsii.

4. Aegilops longissima is closest to Ae. sharonensis and farther from Ae. bicornis and Ae. searsii.

All five species were found to be primarily autogamous. If the outcrossing rate can be roughly estimated as $(1-F) / 2$, then the outcrossing rates vary between 0 and 5 per cent. Zohary \& Imber (1963) reported that large and dense populations of $A e$. speltoides in Israel were predominantly, but not exclusively, allogamous with wind as the main vector. The change from allogamy to autogamy may be explained by the recent decline in the number and size of $A e$. speltoides populations. Whereas 30 years ago the species was common and large dense stands were easily found, today, with the increased usage of land for agriculture, these stands have either disappeared or been reduced to a fraction of their former size. This situation would strongly select for autogamous plants. Similar changes in mating system have been found in tomatoes (Rick et al., 1977).

\section{References}

ALLARD, R. W., KAHLER, A. L. AND WEIR, B. S. 1972. The effect of selection on esterase allozymes in a barley population. Genetics, 72, 489-503.

BAHRMAN, N., ZIVY, M. AND THIELLEMENT, H. 1988. Genetic relationships in the Sitopsis section of Triticum and the origin of the B genome of polyploid wheats. Heredity, 61, 473-480.

BRODY, T. AND MENDLINGER, S. 1980. Species relationships and genetic variation in the diploid wheats as revealed by starch gel electrophoresis. Pl. Syst. Evol., 136, 247-258.

BROWN, A. H. D., MARSHALl, D. R. AND MUNDAY, J. 1976. Adaptedness of variants of an alcohol dehydrogenase locus in Bromus mollis. Aust. J. Biol. Sci., 29, 389-396.

CHAPMAN, V., MILLER, T. E. AND RILEY, R. 1976. Equivalence of the A genome of bread wheat with that of Triticum urartu. Genet. Res., 27, 69-76.

COX, T. S., HATCHETT, J. H., GILL, B. S., RAUP, W. J. AND SEARS, R. G. 1990. Agronomic performances of hexaploid wheat lines derived from direct crosses between wheat and Aegilops squarrosa. Pl. Breed., 105, 271-277. 
DeBENEDICTIS, P. A. 1978. Are populations characterized by their genes or by their genotypes? Am. Nat., 112, $155-175$.

DVORAK, J., ROSS, K. AND MENDLINGER, s. 1985. Transfer of salt tolerance from Elytrigia pontica to wheat by the addition of an incomplete Elytrigia genome. Crop Sci., 25, 306-309.

DVORAK, J., McGUIRE, P. E. AND CASSIDY, B. 1988. Apparent sources of the A genomes of wheats inferred from polymorphism in abundance and restriction fragment length of repeated nucleotide sequences. Genome, 30, 680-689.

DYCK, P. L., KERBER, E. R. AND MARTENS, J. W. 1990. Transfer of a gene for stem rust resistance from Aegilops caudata to common wheat. Can. J. Plant Sci., 70, 931-934.

FELDMAN, M. AND KisleV, M. 1977. Aegilops searsii, a new species of native Sitopsis (Platystuchys). Isr. J. Bot., 26, 190-201.

FRANKEL, O. H. AND BENNETT, E. (EDS) 1970. Genetic Resources in Plants - their Exploration and Conservation. IBP Handbook No. 11. Blackwell Scientific Publications, Oxford.

FRANKEL, O. H. AND HAWKES, J. G. 1975. Crop Genetic Resources for Today and Tomorrow. Cambridge University Press, Cambridge.

GILL, B. S. AND KIMBER, G. 1974. Giemsa C-banding and the evolution of wheat. Proc. Natl. Acad. Sci. U.S.A., 71, 4086-4090.

HAMRICK, J. L. 1983. The distributions of genetic variations within and among natural plant populations. In: Schonewald-Cox, C. M., Chambers, S. M., MacBryde, B. and Thomas, W. L. (eds) Genetic Variation. Benjamin/ Cummings, London.

Johnson, B. L. 1972. Protein electrophoretic profiles and the origin of the B genome in wheat. Proc. Natl. Acad. Sci. U.S.A., 69, 1398-1402.

Johnson, B. L. 1975. Identification of the apparent B-genome donor of wheat. Can. J. Genet. Cytol., 17, 21-39.

KERBY, K. AND KUSPIRA, J. 1988. Cytological evidence bearing on the origin of the $\mathrm{B}$ genome in polyploid wheats. Genome, 30, 36-43.

KERBY, K., KUSPIRA, J., JONES, B. L. AND LOOKHART, G. L. 1990. Biochemical data bearing on the origin of the $B$ genome in the polyploid wheats. Genome, 33, 360-368.

KimURA, M. AND OHTA, T. 1971. Theoretical Aspects of Population Genetics. Monographs in Population Biology No. 4. Princeton University Press, Princeton, NJ.

KUSHNIR, U. AND HALloRAN, G. M. 1981. Evidence for Aegilops sharonensis as the donor of the B genome of wheat. Genetics, 99, 495-512.

LEWONTIN, R. C. 1972. The apportionment of human diversity. Evol. Biol., 6, 381-398.

LEWONTIN, R. C. 1974. The Genetic Basis of Evolutionary Change. Columbia University Press, New York.

MELBURN, M. C. AND THOMPSON, w. P. 1927. The cytology of a tetraploid wheat hybrid (T. spelta $\times T$. monococcum). Am J. Bot., 14, 327-333.

MORRIS, R. AND SEARS, E. R. 1967. The cytogenetics of wheat and its relatives. In: Quisenberry, R. S. and Reitz, L. P. (eds) Wheat and Wheat Improvement, pp 19-85. American Society of Agronomy, Madison, WI.
NAKAI, Y. 1979. Isozyme variation in Aegilops and Triticum. Origin of common wheats revealed from the study on esterase isozymes in synthesized hexaploid wheat. Jap. $J$. Genet., 54, 175-190

NATH, J., HANZEl, J. J., THOMPSON, J. P. AND McKAY, J. W. 1984. Additional evidence implicating Triticum searsii as the B genome donor to wheat. Biochem. Genet., 22, 37-50.

NEI, M. 1972. Genetic distance between populations. Am. Nat., 106, 283-292.

NEVO, E., BEILES, A. AND KAPLAN, D. 1988. Genetic diversity and environmental associations of wild emmer wheat, in Turkey. Heredity, 61, 31-45.

NEVo, E., CARVER, B. F. AND BeILIES, A. 1991. Photosynthetic performance in wild emmer wheat, Triticum dicoccoides: ecological and genetical predictables. Theor. Appl. Genet., 81, 445-460.

NEVO, E., GOLENBERG, E. M., BEILES, A., BROWN, A. H. D. AND ZOHARY, D. 1982. Genetic diversity and environmental associations of wild wheats, Triticum dicoccoides, in Israel. Theor. Appl. Genet., 62, 241-254.

NEVO, E., ZOHARY, D., BROWN, A. H. D. AND HABER, M. 1979. Genetic diversity and environmental associations of wild barley, Hordeum spontaneum, in Israel. Evolution, 33, 815-833.

NISHIKAWA, K. 1983. Species relationship of wheat and its putative ancestors as viewed from isozyme variation. In: Sakamoto, S. (ed.) Proceedings of the 6th Int. Wheat Genet. Symposium, pp. 59-63. Kyoto University, Kyoto, Japan.

PATHAK, N. 1940. Studies in the cytology of cereals. J. Genet., 39, 437-467.

RICK, C. M., FOBES, J. F. AND HOLLE, M. 1977. Genetic variation in Lycopersicon pimpinellifolium: evidence of evolutionary change in mating systems. Pl. Syst. Evol., 127, 139-170.

RILEY, R. 1965. Cytogenetics and evolution of wheat. In: Hutchinson, J. B. (ed.) Essays on Crop Plant Evolution, pp. 103-122. Cambridge University Press, Cambridge.

RILEY, R., UNRAU, J. AND CHAPMAN, v. 1958. Evidence on the origin of the B genome of wheat. J. Hered., 49, 91-98.

SCHAAL, B. A. 1975. Population structure and local differentiation in Liatris cylindracea. Am. Nat., 109, 511-528.

SEARS, E. R. 1948. The cytology and genetics of the wheats and their relatives. Adv. Genet., 2, 239-270.

SEARS, E. R. 1969. Wheat cytogenetics. Ann. Rev. Genet., 3, 451-466.

SEGAL, A., MANISTERSKI, J., FISHBECK, G. AND WAHL, I. 1980. How plant populations defend themselves in natural populations. Plant Disease, V, 75-102.

simmonds, N. w. 1976. Evolution of Crop Plants. Longman, London.

TSUNEWAKI, K. AND OGIHARA, Y. 1983. The molecular basis of genetic diversity among cytoplasms of Triticum and Aegilops species. On the origin of polyploid wheat cytoplasms as suggested by chloroplast DNA restriction fragment patterns. Genetics, 104, 155-177.

VAKHITOV, V. A. AND GIMALOV, F. R. 1988. Polymorphism of the length of the 5S ribosomal RNA gene in genomes of different wheat and Aegilops species. Genetika, 24, 1850-1856.

YEN, Y. AND KIMBER, G. 1990. Genomic relationships of 
Triticum searsii to other S-genome diploid Triticum species. Genome, 33, 369-373.

ZOHARY, D. 1965. Colonizing species in the wheat groups. In: Baker, H. G. and Stebbins, G. L. (eds) The Genetics of Colonizing Species. Academic Press, New York
ZOHARY, D., HARLAN, J. R. AND VARDI, A. 1969. The wild diploid progenitors of wheat and their breeding value. Euphytica, $18,58-65$.

ZOHARY, D. AND IMBER, D. 1963. Genetic dimorphism in fruit types in Aegilops speltoides. Heredity, 18, 223-231. 